\title{
Protective roles of ascorbic acid in oxidative stress induced by depletion of superoxide dismutase in vertebrate cells.
}

\section{AUTHOR(S):}

Tamari, Yuki; Nawata, Hisakatsu; Inoue, Eri; Yoshimura, Akari; Yoshii, Hanako; Kashino, Genro; Seki, Masayuki; Enomoto, Takemi; Watanabe, Masami; Tano, Keizo

\section{CITATION:}

Tamari, Yuki ...[et al]. Protective roles of ascorbic acid in oxidative stress induced by depletion of superoxide dismutase in vertebrate cells.. Free radical research 2013, 47(1): 17

\section{ISSUE DATE:}

2013-01

URL:

http://hdl.handle.net/2433/184461

\section{RIGHT:}

C 2013 Informa UK, Ltd.; この論文は出版社版でありません。引用の際 には出版社版をご確認ご利用ください。; This is not the published version. Please cite only the published version. 
Protective roles of ascorbic acid in oxidative stress induced by depletion of superoxide dismutase in vertebrate cells

Yuki Tamari ${ }^{\mathrm{a}}$, Hisakatsu Nawata ${ }^{\mathrm{a}}$, Eri Inoue ${ }^{\mathrm{b}}$, Akari Yoshimura ${ }^{\mathrm{c}}$, Hanako Yoshii ${ }^{\mathrm{a}}$, Genro Kashino, ${ }^{\mathrm{a}, \mathrm{d}}$, Masayuki Seki ${ }^{\mathrm{b}}$, Takemi Enomoto ${ }^{\mathrm{c}}$, Masami Watanabe ${ }^{\mathrm{a}}$, Keizo Tano $^{\mathrm{a} *}$

\section{Institution}

a'Laboratory of Radiation Biology, Division of Radiation Life Science, Research Reactor Institute, Kyoto University, 2-1010, Asashiro-Nishi, Kumatori-cho, Sennan-gun, Osaka 590-0494, Japan.

${ }^{b}$ Molecular Cell Biology Laboratory, Graduate School of Pharmaceutical Sciences, Tohoku University, 6-3, Aoba, Aramaki, Aoba-ku, Sendai city, Miyagi 980-8578, Japan.

${ }^{c}$ Molecular Cell Biology Laboratory, Research Institute of Pharmaceutical Science, Faculty of Pharmaceutical Sciences, Musashino University, 1-1-20, Shin-machi, Nishitokyo city, Tokyo 202-8585, Japan.

dAdvanced Molecular Imaging Center, Medical School, Oita University, 1-1, Idaiga-oka, Hasama-machi, Yufu city, Oita 879-5593, Japan.

*Corresponding author

Keizo Tano

Laboratory of Radiation Biology, Division of Radiation Life Science, Research Reactor Institute, Kyoto University, 2-1010 Kumatori-cho, Sennan-gun, Osaka 590-0494, Japan.

Tel.: +81-72-451-2392

Fax: +81-72-451-2628

E-mail: tano@ rri.kyoto-u.ac.jp 


\section{Key words}

SOD1, SOD2, antioxidant, DT40, conditional knockout cell 


\section{Abstract}

Superoxide dismutases (SODs) are antioxidant proteins that convert superoxide to hydrogen peroxide. In vertebrate cells, SOD1 is mainly present in the cytoplasm, with small levels also found in the nucleus and mitochondrial inter-membrane space, and SOD2 is present in the mitochondrial matrix. Previously, we conditionally disrupted the SODI or SOD2 gene in DT40 cells and found that depletion of SOD1 caused lethality, while depletion of SOD2 led to growth retardation. Our observations from previous work showed that the lethality observed in SOD1-depleted cells was completely rescued by ascorbic acid. Ascorbic acid is a water-soluble antioxidant present in biological fluids; however, the exact target for its antioxidant effects is not known. In this study, we demonstrated that ascorbic acid offset growth defects observed in SOD2-depleted cells and also lowered mitochondrial superoxide to physiological levels in both SOD1- or SOD2-depleted cells. Moreover, depletion of SOD1 or SOD2 resulted in the accumulation of intracellular oxidative stress, and this increased oxidative stress was reduced by ascorbic acid. Taken together, this study suggests that ascorbic acid can be applied as a nontoxic antioxidant that mimics the functions of cytoplasmic and mitochondrial SODs.

\section{Introduction}

Aerobic organisms have evolutionally acquired antioxidant systems against reactive oxygen species (ROS) produced during normal metabolism, especially as a consequence of aerobic respiration in mitochondria. Although physiological amounts of ROS are necessary in aerobic organisms for cell signaling pathways and killing invading pathogens, excessive concentrations of ROS are considered to be an "oxidative stress", damaging macromolecules such as DNA, proteins, and lipids [1-6]. The enzymes of superoxide dismutase (SOD) families are the first and most important endogenous antioxidants, converting superoxide 
anions to hydrogen peroxide [7]. In mammalian cells, three types of SOD have been identified [8]. SOD1 is the major intracellular $\mathrm{Cu} / \mathrm{Zn}$-dependent SOD located in nuclei and the mitochondrial inter-membrane space. Immunocytochemical analysis showed that SOD1 is also localized in lysosomes and peroxisomes [9-12]. SOD2 is an Mn-dependent SOD localized in the mitochondrial matrix where it is involved in "dismutating" superoxide generated by the respiratory chain $[13,14]$. SOD3 is an extracellular $\mathrm{Cu} / \mathrm{Zn}$-dependent SOD located in the vascular extracellular space $[8,15]$.

Oxidative stress resulting from an imbalance between superoxide and endogenous antioxidants has been widely considered to be involved in a number of diseases such as neurodegenerative disorders, cardiovascular dysfunction [16-19], and cancer development and progression [20,21]. In fact, nitric oxide, with anti-inflammatory and anti-coagulant properties, is rapidly inactivated by superoxide and converted to the strong oxidant peroxynitrite. Increasing evidence for the involvement of ROS in pathological conditions has been accompanied by searches for the antioxidant potential of natural as well as synthetic compounds.

Vitamin $\mathrm{C}$ is a water-soluble antioxidant and is also a cofactor for various enzymes [22]. Ascorbic acid, which is the reduced form of vitamin $\mathrm{C}$, is a predominant chemical structure in biological fluids [23,24]. Although ascorbic acid is a potent antioxidant quenching potentially damaging ROS produced by normal metabolism [25,26], it also acts as a prooxidant, promoting the formation of many ROS, such as hydrogen peroxide and hydroxyl radicals [27-29].

The protective effects of ascorbic acid are believed to occur by scavenging ROS induced by various sources [22,30-32]. An increasing amount of data supports the scavenging ability of ascorbic acid; however, specific ROS species scavenged by ascorbic acid have not yet been identified. Previously, we constructed cell lines in which expression of either SOD1 or 
SOD2 could be switched off by doxycycline (DOX) treatment in chicken DT 40 cells [33,34]. The availability of these cell lines allows us to specifically examine the biological effects of endogenous superoxide. We showed that SOD1 was essential for cell viability [34] and SOD2-depleted cells were viable, but exhibited slow growth [33]. Interestingly, we found that growth disturbances observed with SOD1-depleted cells were completely suppressed by ascorbic acid. These results suggested that ascorbic acid reduced elevated intracellular levels of superoxide caused by the depletion of SOD1.

In this study, we examine the effects of ascorbic acid in SOD2-depleted cells. Our data clearly showed that ascorbic acid effectively offset cellular phenotypes caused by the depletion of SOD1 or SOD2, including increased levels of superoxide and mitochondrial dysfunction as well as growth disturbances. This data demonstrates that ascorbic acid mimics the functions of cytoplasmic or mitochondrial SOD in chicken DT40 cells.

\section{Materials and Methods}

\section{Cell culture}

Cells were cultured in RPMI 1640 supplemented with $10 \%$ fetal bovine serum, $1 \%$ chicken serum, and kanamycin at $39{ }^{\circ} \mathrm{C}$ under $5 \% \mathrm{CO}_{2}$. Conditional SOD1- and SOD2-knock-out DT40 cells were established as described previously [33,34] and the expression of transgenic human SOD1 and human SOD2 was suppressed by treatment with 1 $\mu \mathrm{g} / \mathrm{ml}$ DOX. Ascorbic acid phosphate ester magnesium salt (APM) (Wako Pure Chemical Industries Ltd., Osaka, Japan) was dissolved in phosphate buffered saline (PBS): $137 \mathrm{mM}$ $\mathrm{NaCl}, 2.68 \mathrm{mM} \mathrm{KCl}, 8.04 \mathrm{mM} \mathrm{Na}_{2} \mathrm{HPO}_{4}$, and $1.47 \mathrm{mM} \mathrm{KH}_{2} \mathrm{PO}_{4}$. To assay the effect of various antioxidants, cells cultured in the presence or absence of DOX for the indicated periods were treated with $200 \mu \mathrm{M}$ APM, 5 mM N-acetyl-L-cysteine (NAC, Wako, Osaka, Japan), $50 \mu \mathrm{M}$ 6-hydroxy-2,5,7,8-tetramethylchroman- 2-carboxylic acid (Trolox, 
Sigma-Aldrich), $250 \mu \mathrm{M}$ 1,2-Dihydroxy-3,5-benzenedisulfonic acid (Tiron, Sigma-Aldrich), or $50 \mu \mathrm{M}$ 2-mercaptoethanol (EtSH, Sigma-Aldrich). The generation of growth curves has been described previously $[33,34]$.

\section{Superoxide assay}

Intracellular generation of superoxide was detected using BES-So-AM (Wako Pure Chemical Industries Ltd.), a highly specific fluorescent probe for superoxide [35]. Briefly, cells were treated with $5 \mu \mathrm{M}$ BES-So-AM for $20 \mathrm{~min}$. After washing twice with PBS, cells were suspended in PBS, and fluorescent intensity was measured using FACScan (Becton Dickinson, Franklin Lakes, NJ, USA) [35]. Mitochondrial superoxide levels were measured by flow cytometry (FACS) after staining with the mitochondrial superoxide-specific dye MitoSOX red (Invitrogen). Cells were washed with PBS and incubated with $5 \mu \mathrm{M}$ MitoSOX red for 10 min. Measurements were performed using FACScan (Becton Dickinson, Franklin Lakes, NJ, USA). MitoSOX red was excited at $396 \mathrm{~nm}$ [36] and data was collected in the 580/510 nm (FL2) channel. Quantifications were performed from the mean intensity of MitoSOX fluorescence from triplicates.

\section{Measurement of Mitochondrial Membrane Potential}

Mitochondrial membrane potential was measured using 5, 5', 6, 6'-tetrachloro-1, 1', 3, 3'-tetraethyl- benzimidazoylcarbocyanine iodide (JC-1; Molecular Probes, Eugene, USA) as previously described [37]. JC-1 is a cationic carbocyanine dye that presents itself as green fluorescent monomers at a low concentration (i.e., in cells with low mitochondrial functions or membrane potential). In cells with normal mitochondrial functions, a membrane potential-driven accumulation of these dyes results in the formation of yellowish-red fluorescent J-aggregates. Briefly, cells were washed with cold PBS and incubated with $5 \mu \mathrm{M}$ 
JC-1 for 30 min at $37^{\circ} \mathrm{C}$. After washing twice with cold PBS, cells were harvested and the intensity of fluorescence was analyzed using a FACScan (Becton Dickinson, Franklin Lakes, NJ) with excitation at $490 \mathrm{~nm}$ and emission at $530 \mathrm{~nm}$.

\section{Determination of intracellular ROS levels}

Intracellular ROS were measured using 2',7'-dichlorodihydrofluorescein diacetate (DCFH-DA; Molecular Probes, USA). Intracellular peroxide-dependent oxidation converts DCFH-DA to the fluorescent compound 2',7'-dichlorofluorescein (DCF), as previously described [37]. After washing twice with PBS, cells were incubated with DCFA-DA $(20 \mu \mathrm{M})$ for $30 \mathrm{~min}$ at $37^{\circ} \mathrm{C}$. After incubation, cells were harvested and resuspended in $50 \mathrm{mM}$ HEPES buffer (5 mM HEPES, pH 7.4, $5 \mathrm{mM} \mathrm{KCl,} 140 \mathrm{mM} \mathrm{NaCl}, 2 \mathrm{mM} \mathrm{CaCl} 2,1 \mathrm{mM}$ $\mathrm{MgCl}_{2}$, and $10 \mathrm{mM}$ glucose). The fluorescence intensity was determined using FACScan (Becton Dickinson, Franklin Lakes, NJ) with excitation at $485 \mathrm{~nm}$ and emission at $530 \mathrm{~nm}$.

\section{Results and Discussion}

\section{Ascorbic Acid relief of growth perturbations in both SOD1 and SOD2 depleted cells}

Previously, we generated conditional $S O D 1^{-/}$and $S O D 2^{-/}$cells in which the human SOD1 or SOD2 trans-gene was expressed under control of the tetracycline inducible promoter. Expression of each SOD trans-gene can be switched off by the addition of DOX leading to the complete depletion of exogenous SOD proteins [33,34]. These cells enable us to characterize cellular phenotypes caused by endogenous increases in superoxide due to the absence of SOD activity. Our previous work showed that SOD1 was essential for cell viability whereas SOD2 was not, but it was required for normal cell growth. Our observation from previous work is that the lethality observed in SOD1-depleted cells was completely rescued in the presence of ascorbic acid, Ascorbic acid phosphate ester magnesium salt 
(APM) [34]. Ascorbic acid in aqueous solution can be oxidized easily and can be stabilized by phosphorylation [38]. Ascorbic acid phosphate has been used as a non-autooxidizable form of vitamin $\mathrm{C}$ in several cell culture studies including our previous studies $[32,39]$. To examine the effects of ascorbic acid on SOD2-depleted cells, we analyzed the mode of cell growth of SOD2-depleted cells in the presence of ascorbic acid. In spite of the different cellular localizations of SOD1 and SOD2, we found that ascorbic acid fully recovered the growth delay observed in SOD2-depleted cells (Figure 1B). We confirmed that SOD2 $2^{-/}$ hSOD2 cells without DOX treatment proliferated normally in the presence of ascorbic acid (Supplemental Fig. S1). To examine other antioxidants for the rescue of growth deficiencies observed in SOD1-depleted or SOD2-depleted cells, we compared the growth properties of these cells in the presence of several antioxidants, NAC (N-acetyl-L-cysteine), a nontoxic dietary glutathione precursor, Tiron (4,5-dihydroxy-1,3-benzene disulfonic acid), a widely used antioxidant, and Trolox (6-hydroxy-2,5,7,8-tetramethylchroman-2-carboxylic acid), a cell-permeable, water-soluble vitamin E derivative. 2-Mercaptoethanol is a strong reducing agent for disulfide bonds and has antioxidant capacity by scavenging hydroxyl radicals. As shown in Figure 1, none of these antioxidants, except for ascorbic acid, rescued both SOD1-depleted cells and SOD2-depleted cells (Figure 1A and 1B). We should mention that original wild type cells proliferated normally in the absence or presence of DOX and/or ascorbic acid (Supplemental Fig. S2) or other antioxidants (data not shown).

Figure 1

Ascorbic acid suppresses increased mitochondrial or cellular superoxide levels in SOD1 or SOD2 depleted cells.

Ascorbic acid is known to be a non-enzymatic antioxidant exerting anti-mutagenic effects 
by scavenging organic radicals $[39,40]$. We previously measured intracellular levels of superoxide using BES-So-AM and found that the levels of superoxide were increased in SOD1-depleted cells. These elevated superoxide levels were completely suppressed by ascorbic acid without changing the efficacy of suppression of the expression of hSOD1 by the tet-off promoter [34]. Even though BES-So-AM is a more practical superoxide probe than others, it should not rule out the possibility that BES-So-AM exhibited a fluorescent response to hydroxyl radicals in addition to superoxide [35]. In contrast to SOD1-depeleted cells, we found that superoxide levels in the cytoplasm were not altered in SOD2-depleted cells. We speculated that it was probably due to the exclusive localization of SOD2 in the mitochondrial matrix (Figure 2A).

Next, we measured superoxide levels in mitochondria by the Mito-SOX red oxidation method. Superoxide levels in mitochondria were significantly elevated in SOD2-depleted cells, while there was no change in the level of superoxide in the cytoplasm (Figure 2B). Superoxide levels in mitochondria were also elevated in SOD1-depleted cells (Figure 2B). This data demonstrated that a SOD deficiency elevates the level of superoxide in mitochondria.

We examined whether ascorbic acid suppresses the increased superoxide levels in mitochondria as efficiently as that in the cytoplasm. As shown in Figure 2B, increased superoxide levels in mitochondria, both in SOD1-depleted and SOD2-depleted cells were completely suppressed by ascorbic acid. These results indicate that ascorbic acid scavenges superoxide in mitochondria effectively and helps maintain a physiological level of superoxide.

Figure 2 
Increased mitochondrial superoxide levels could induce dysfunctions in mitochondria. The mitochondrial membrane potential $(\Delta \Psi)$ is an important criterion for assessing mitochondrial function and has been used as an indicator of mitochondrial integrity. To determine the impact of elevated mitochondrial superoxide levels on mitochondrial function, the mitochondrial membrane potential $(\Delta \Psi)$ was analyzed using a unique cationic dye, JC-1 (5,5',6,6'-tetrachloro-1,1',3,3'- tetraethylbenzimidazolylcarbocyanine iodide). Significantly, abnormal up-transitions in mitochondrial permeability were observed in SOD2-depleted cells. While similar elevated superoxide levels in mitochondria were detected in SOD $1^{-1}$ hSOD1-depleted cells (Figure 3), no significant change in the mitochondrial membrane potential was observed in SOD1-depleted cells (Figure 3). Elevations in $\Delta \Psi$ or mitochondrial hyperpolarization are an indication of abnormal mitochondrial status. For example, systemic lupus erythematosus is characterized by abnormal T-cell activation and cell death, which depend on the controlled production of ROS intermediates and ATP in mitochondria; lupus T-cells exhibit mitochondrial dysfunction and persistent elevations in mitochondrial membrane potential that predisposes lupus T-cells to cell death [41]. It has been assumed that increased levels of superoxide, due to the depletion of SOD2, generate cellular circumstances similar to those in lupus T-cells. Because SOD1 and SOD2 are localized in different mitochondrial fractions, the mitochondrial inter-membrane and matrix respectively, these results suggest that increased superoxide in the mitochondrial matrix is more harmful to mitochondrial function than that in the mitochondrial inter-membrane. SOD2 may play a critical role in maintaining superoxide levels in the mitochondrial matrix, thereby protecting mitochondria. The abnormal mitochondrial membrane potential observed in SOD2-depleted cells was completely recovered by treatment with ascorbic acid. Ascorbic acid scavenges superoxide effectively in mitochondria and maintains superoxide in mitochondria at physiological levels, keeping the mitochondrial membrane potential at 
normal levels in the absence of SOD2 in DT 40 cells.

Figure 3

\section{Ascorbic acid suppresses overall increased oxidative stress in SOD1 or SOD2 depleted cells}

Inadequate removal of reactive oxygen species (ROS) could result in overall oxidative stress in cells. However, superoxide itself is not highly reactive and impermeable $[42,43,44]$. An increased level of superoxide triggered by a SOD deficiency could generate other secondary ROS, leading to elevations in overall oxidative stress. It is known that secondary ROS derived from superoxide, such as hydrogen peroxide and hydroxyl radicals, are more reactive and penetrate biological membranes more efficiently than superoxide $[42,44]$. In addition, superoxide reacts with nitric oxide (NO), produced as a consequence of oxidative stress, and strong oxidants such as peroxynitrite $\left(\mathrm{ONOO}^{-}\right)$are produced. To examine the overall levels of oxidative stress, we stained SOD1-depleted or SOD2-depleted cells with dichlorodihydrofluorescein (DCFH). DCFH is a cell-permeable fluorescence dye and reacts with a broad spectrum of cellular ROS. Overall oxidative stress was increased both in SOD1-depleted and SOD2-depleted cells. Unexpectedly, a higher level of oxidative stress was detected in SOD2-depleted cells than in SOD1-depleted cells, even though a similar level of superoxide was detected (Figure 4). It is not clear what accounts for this difference in the two cell-lines; we would like to suggest the possibility that potential molecules that become ROS after interacting with superoxide may be more abundant in the mitochondrial matrix than those in the mitochondrial inter-membrane space. This data may also indicate that secondary ROS generated by superoxide, not superoxide itself, causes the abnormal mitochondrial membrane potential observed in SOD2-depleted cells (Figure 3).

Importantly, ascorbic acid suppressed increased levels of oxidative stress and maintained 
oxidative stress at physiological levels both in SOD1-depleted and SOD2-depleted cells (Figure 4). Ascorbic acid suppresses the formation of secondary ROS by scavenging superoxide and lowers the level of overall oxidative stress in SOD depleted cells.

Figure 4

Oxidative stress and mitochondrial dysfunction have been linked to neurodegenerative disorders, such as Parkinson's and Alzheimer's diseases [45,46]. Recently, it was reported that Sirt3-dependent mitochondrial SOD2 activity is an important factor in preventing cancer permissive circumstances [47]. Accumulated evidence for the involvement of oxidative stress in various pathological conditions has encouraged the search for natural and synthetic antioxidants as well as the antioxidant potentials of natural products. Thus, developing screening systems that specifically identify molecules/chemicals that can replace SOD functions is vital. In conclusion, we showed that ascorbic acid scavenges superoxide in the cytoplasm and mitochondria effectively and restores physiological levels of superoxide and oxidative stress in SOD-deficient cells, thereby "mimicking" the enzymatic functions of SODs. Our SOD1-depleted and SOD2-depleted cell lines should be powerful tools for screening and identifying molecules/chemicals that mimic the functions of SODs.

\section{Acknowledgments}

We thank Drs. Tadayoshi Bessho, Samuel Wilson, and Shunichi Takeda for their critical reading of this manuscript and Noriko Tano for her expert secretarial assistance. This work was supported by grants for Scientific Research from the Ministry of Education, Culture, Sports, Science, and Technology of Japan (21310036, 20510051, 24510072) and for The Nuclear Safety Research Enhancement Actions from the Nuclear Safety Commission of 
Japan. 


\section{References}

[1] Go YM, Jones DP. Cysteine/cystine redox signaling in cardiovascular disease. Free Radic Biol Med 2011;50:495-509.

[2] Lassegue B, Griendling KK. NADPH oxidases: functions and pathologies in the vasculature. Arterioscler Thromb Vasc Biol 2010;30:653-661.

[3] Ushio-Fukai M. Compartmentalization of redox signaling through NADPH oxidase-derived ROS. Antioxid Redox Signal 2009;11:1289-1299.

[4] Woo HA, Yim SH, Shin DH, Kang DH, Yu DY, Rhee SG. Inactivation of peroxiredoxin I by phosphorylation allows localized $\mathrm{H}_{2} \mathrm{O}_{2}$ accumulation for cell signaling. Cell 2010;140: $517-528$.

[5] Finkel T, Holbrook NJ. Oxidants, oxidative stress and the biology of ageing. Nature 2000;408:239-247.

[6] Marnett LJ, Plastaras JP. Endogenous DNA damage and mutation. Trends in Genet 2001;117:214-221.

[7] Buettner GR. Superoxide dismutase in Redox Biology: The roles of superoxide and hydrogen peroxide. Anticancer Agents Med Chem 2011;11:341-346.

[8] Zelko IN, Mariani TJ, Folz RJ. Superoxide dismutase multigene family: a comparison of the CuZn-SOD (SOD1), Mn-SOD (SOD2), and EC-SOD (SOD3) gene structures, evolution, and expression. Free Radic Biol Med 2002;33:337-349.

[9] Crapo JD, Oury T, Rabouille C, Slot JW, Chang LY. Copper,zinc superoxide dismutase is primarily a cytosolic protein in human cells. Proc Natl Acad Sci USA 1992;89:10405-10409. [10] Okado-Matsumoto A, Fridovich I. Subcellular distribution of superoxide dismutases (SOD) in rat liver: Cu,Zn-SOD in mitochondria. J Biol Chem 2001;276:38388-38393. [11] Sturtz LA, Diekert K, Jensen LT, Lill R, Culotta VC. A fraction of yeast $\mathrm{Cu}, \mathrm{Zn}$-superoxide dismutase and its metallochaperone, $\mathrm{CCS}$, localize to the intermembrane 
space of mitochondria. A physiological role for SOD1 in guarding against mitochondrial oxidative damage. J Biol Chem 2001;276:38084-38089.

[12] Chang LY, Slot JW, Geuze HJ, Crapo JD. Molecular immunocytochemistry of the CuZn superoxide dismutase in rat hepatocytes. J Cell Biol 1988;107:2169-2179.

[13] Fridovich I, Freeman B. Antioxidant defenses in the lung. Annu Rev Physiol 1986;48:693-702.

[14] Weisiger RA, Fridovich I. Superoxide dismutase. Organelle specificity. J Biol Chem $1973 ; 248: 3582-3592$.

[15] Marklund SL, Holme E, Hellner L. Superoxide dismutase in extracellular fluids. Clin Chim Acta 1982;126:41-51.

[16] Qin Z, Gongora MC, Ozumi K, Itoh S, Akram K, Ushio-Fukai M, Harrison DG, Fukai T. Role of Menkes ATPase in angiotensin II-induced hypertension: a key modulator for extracellular superoxide dismutase function. Hypertension 2008;52:811-812.

[17] Kalmar B, Novoselov S, Gray A, Cheetham ME, Margulis B, Greensmith L. Late stage treatment with arimoclomol delays disease progression and prevents protein aggregation in the SOD1 mouse model of ALS. J Neurochem 2008;107:339-350.

[18] Joseph A, Li Y, Koo HC, Davis JM, Pollack S, Kazzaz JA. Superoxide dismutase attenuates hyperoxia-induced interleukin-8 induction via AP-1. Free Radic Biol Med 2008;45:1143-1149.

[19] Pawlak K, Domaniewski T, Mysliwiec M, Pawlak D. The kynurenines are associated with oxidative stress, inflammation and the prevalence of cardiovascular disease in patients with end-stage renal disease. Atherosclerosis 2008;204:309-314.

[20] Kaewpila S, Venkataraman S, Buettner GR, Oberley LW. Manganese superoxide dismutase modulates hypoxia-inducible factor-1 alpha induction via superoxide. Cancer Res 2008;68:2781-2788. 
[21] Oberley LW. Anticancer therapy by overexpression of superoxide dismutase. Antioxid Redox Signal 2001;3:461-472.

[22] Traber MG, Stevens JF. Vitamin C and E; Beneficial effects from mechanistic perspective. Free Radic Biol Med 2011;51:1000-1013.

[23] Frei B, England L, Ames BN. Ascorbate is an outstanding antioxidant in human blood plasma. Proc Natl Acad Sci USA 1989;86:6377-6381.

[24] Frei B, Stocker R, England L, Ames BN. Ascorbate: the most effective antioxidant in human blood plasma. Adv Exp Med Biol 1990;264:155-163.

[25] Heaney ML, Gardner JR, Karasavvas N, Schneinberg DA, Smith EA, O`Connor OA. Vitamin $\mathrm{C}$ antagonizes the cytotoxic effects of antineoplastic drugs. Cancer Res 2008;68:8031-8038.

[26] Verrax J, Calderon PB. The controversial place of vitamin C in cancer treatment. Biochem Pharmacol 2008;76:1644-1652.

[27] Carr A, Frei B. Does vitamin C act as a pro-oxidant under physiological conditions? FASEB J 1999;13:1007-1024.

[28] Hara S, Mizukami H, Kuriwa F, Endo T. Hydroxyl radical formation on extracellular ascorbate in rat striatum, as determined by microdialysis. Toxicology 2009;258:10-16.

[29] Kang MJ, Lee SS, Koh HC. Prooxidant properties of ascorbic acid in the nigrostriatal dopaminergic system of C57BL/6 mice. Toxicology 2012;294:1-8.

[30] Schneider M, Diemer K, Engelhart K, Zankl H, Trommer WE, Biesalski HK. Protective effects of vitamin $\mathrm{C}$ and $\mathrm{E}$ on the number of micronuclei in lymphocytes in smokers and their role in ascorbate free radical formation. Free Radic Res 2001;34:209-219.

[31] Brennan LA, Morris GM, Wasson GR, Hannigan BM, Barnett YA. The effect of vitamin $\mathrm{C}$ or vitamin $\mathrm{E}$ supplementation on basal and $\mathrm{H}_{2} \mathrm{O}_{2}$-induced DNA damage in human lymphocytes. Br J Nutr 2000;84:195-202. 
[32] Kashino G, Kodama S, Nakayama Y, Suzuki K, Fukase K, Goto M, Watanabe M. Relief of oxidative stress by ascorbic acid delays cellular senescence of normal human and Werner syndrome fibroblast cells. Free Radic Biol Med 2003;35:438-443.

[33] Takada S, Inoue E, Tano K, Yoshii H, Abe T, Yoshimura A, Akita M, Tada S, Watanabe M, Seki M, Enomoto T. Generation and characterization of cells that can be conditionally depleted of mitochondrial SOD2. Biochem Biophys Res Commun 2009;379:233-238.

[34] Inoue E, Tano K, Yoshii H, Nakamura J, Tada S, Watanabe M, Selki M, Enomoto T. SOD1 is essential for viability of DT40 cells and nuclear SOD1 functions as a guardian of genomic DNA. J Nucleic Acid 2010;2010:795946 doi:10.4061/2010/795946.

[35] Maeda H, Yamamoto K, Kohno I, Hafsi L, Nakagawa S, Kanagawa N, Uno T. Design of a practical fluorescent probe for superoxide based on protection deprotection chemistry of fluoresceins with benzenesulfonyl protecting groups. Chemistry 2007;13:1946-1954.

[36] Robinson KM, Janes MS, Pehar M, Monette JS, Ross MF, Hagen TM, Murphy MP, Beckman JS. Selective fluorescent imaging of superoxide in vivo using ethidium-based probes. Proc Natl Acad Sci USA 2006;103:15038-15043.

[37] Yohii H, Watanabe M. Intervention of oxygen-control ability to radiation sensitivity, cell aging and cell transformation. J Radiat Res 2009;50:127-137.

[38] Halliwell B, Gutteridge JMC. Ascorbic acid (vitamin C). In Halliwell B, Gutteridge JMC. Free Radicals in Biology and Medicine. 4th ed. New York: Oxford University Press 2007. p160-166.

[39] Harada T, Kashino G, Suzuki K, Matsuda N, Kodama S, Watanabe M. Different involvement of radical species in irradiated and bystander cells. Int J Radiat Biol 2008;84: 809-814.

[40] Koyama S, Kodama S, Suzuki K, Matsumoto T, Miyazaki T, Watanabe M. Radiation-induced long-lived radicals which cause mutation and transformation. Mutat Res 
$1998 ; 21: 45-54$.

[41] Fernandez D, Perl A. Metabolic control of $\mathrm{T}$ cell activation and death in SLE. Autoimmun Rev 2009;8:184-189.

[42] Nordberg J, Arnér ESJ. Reactive oxygen species, antioxidants, and the mammalian thioredoxin system. Free Radic Biol Med 2001;31:1287-1312.

[43] Missirlis F, Hu J, Kirby K, Hilliker AJ, Rouault TA, Phillips JP. Compartment-specific protection of iron-sulfur proteins by superoxide dismutase. J Biol Chem 2003;278: 47365-47369.

[44] Li J-M, Shah AM. Endothelial cell superoxide generation: regulation and relevance for cardiovascular pathophysiology. Am J Physiol 2004;287:R1014-R1030.

[45] Beal MF. Aging, energy, and oxidative stress in neurodegenerative diseases. Ann Neurol $1995 ; 38: 357-366$.

[46] Hinerfeld D, Traini MD, Weinberger RP, Cochran B, Doctrow SR, Harry J, Melov S. Endogenous mitochondrial oxidative stress: neurodegeneration, proteomic analysis, specific respiratory chain defects, and efficacious antioxidant therapy in superoxide dismutase 2 null mice. J Neurochem 2004;88:657-667.

[47] Tao R, Coleman ML, Pennington JD, Ozen O, Park S-H, Jiang H, Kim H-S, Flynn CR, Hill S, McDonald WH, Oliver AK, Spitz DR, Gius D. Sirt3-Mediated Deacetylation of Evolutionarily Conserved Lysine 122 Regulates MnSOD Activity in Response to Stress. Mol Cell 2010;40:893-904. 


\section{Figure legends}

Figure 1. Effect of antioxidants on the growth curves of SOD1- or SOD2-deleted cells. Indicated knockout cells were cultured with or without $1 \mu \mathrm{g} / \mathrm{ml}$ DOX and/or various antioxidants.

Figure 2. Suppression of increased superoxide levels in SOD1- or SOD2-depleted cells by ascorbic acid. (A) Cytoplasmic superoxide levels in SOD2-depleted cells. Levels of superoxide were measured with BES-So-AM. (B) Mitochondrial superoxide levels in SOD1or SOD2-depleted cells. Mitochondrial superoxide levels in the indicated cells were measured with Mito SOX red. In either case, cells were treated with or without $1 \mu \mathrm{g} / \mathrm{ml}$ DOX and /or $200 \mu \mathrm{M}$ ascorbic acid for 96 hours. Data from flow cytometric analyses are presented as mean fluorescence intensity (MFI). The MFI of cells not treated with DOX was used as the standard (arbitrary unit [a.u.] =1). Error bars indicate standard errors based on three independent experiments.

Figure 3. Normalization of up-shifted mitochondrial membrane potential in SOD1- or SOD2-depleted cells. Cells were treated with or without $1 \mu \mathrm{g} / \mathrm{ml}$ DOX and /or $200 \mu \mathrm{M}$ ascorbic acid for 96 hours. The mitochondrial membrane potential $(\Delta \Psi \mathrm{m})$ was assessed with JC-1. The ratio of red to green fluorescence is a semiquantitative indicator of $\Delta \Psi \mathrm{m}$. Mean green fluorescence (FL-1 channel) and mean orange-red fluorescence (FL-2 channel) were quantified using flow cytometry. $\Psi \mathrm{m}$ was expressed as the mean red to mean green fluorescence ratio. $\Psi \mathrm{m}$ of cells not treated with DOX was used as the standard (a.u. = 1). Error bars indicate standard errors based on three independent experiments.

Figure 4. Suppression of increased cellular oxidative stress in SOD1- or SOD2-depleted cells 
by ascorbic acid. Cells were treated with or without $1 \mu \mathrm{g} / \mathrm{ml}$ DOX and /or $200 \mu \mathrm{M}$ ascorbic acid for 96 hours. Cellular oxidative stress generated within cells was detected using the fluorescent probe DCFH oxidation. Data from flow cytometric analyses are presented as MFI. The MFI of cells not treated with DOX was used as the standard (a.u.=1). Error bars indicate standard errors based on three independent experiments. 
Figure 1
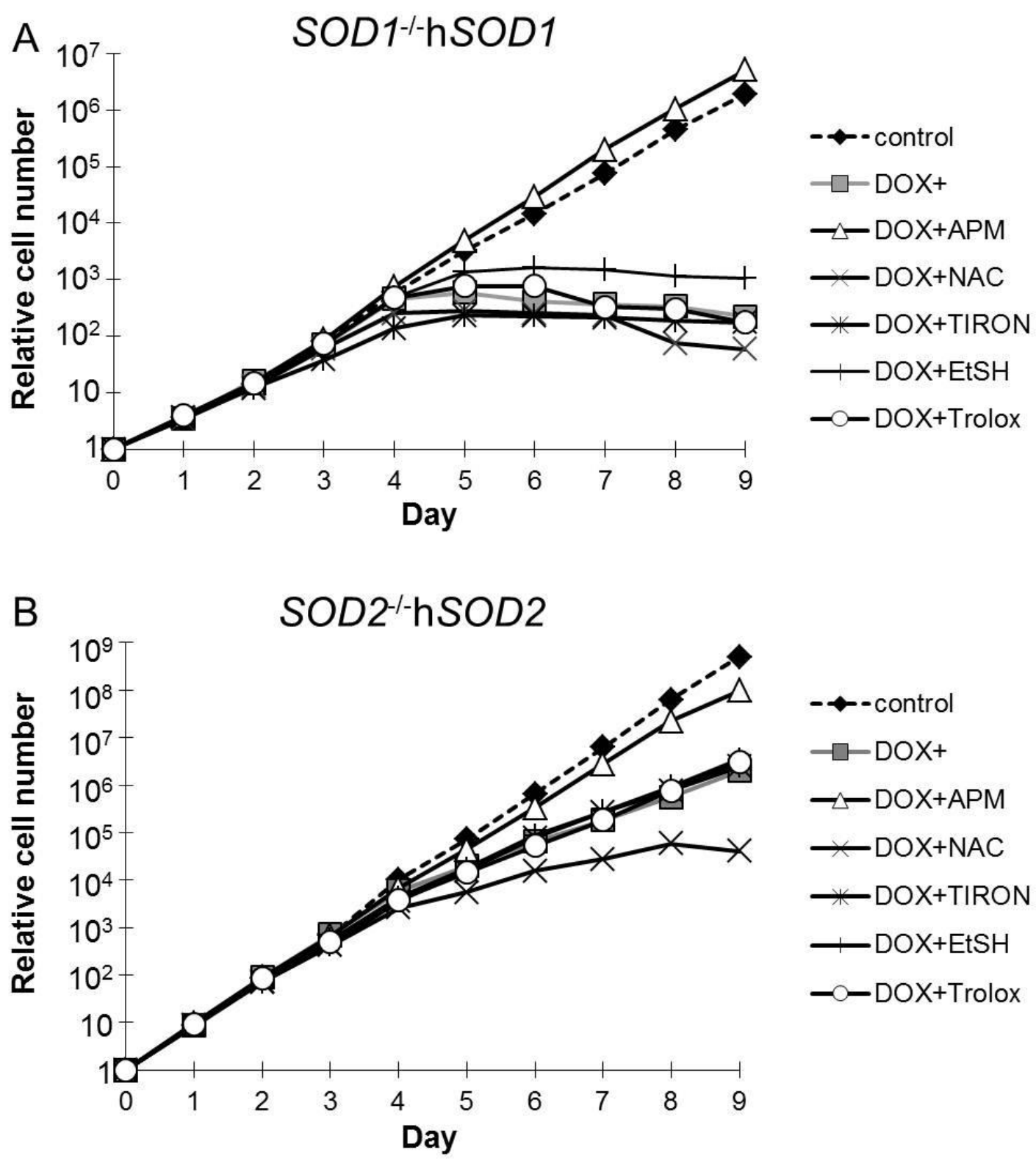
Figure 2
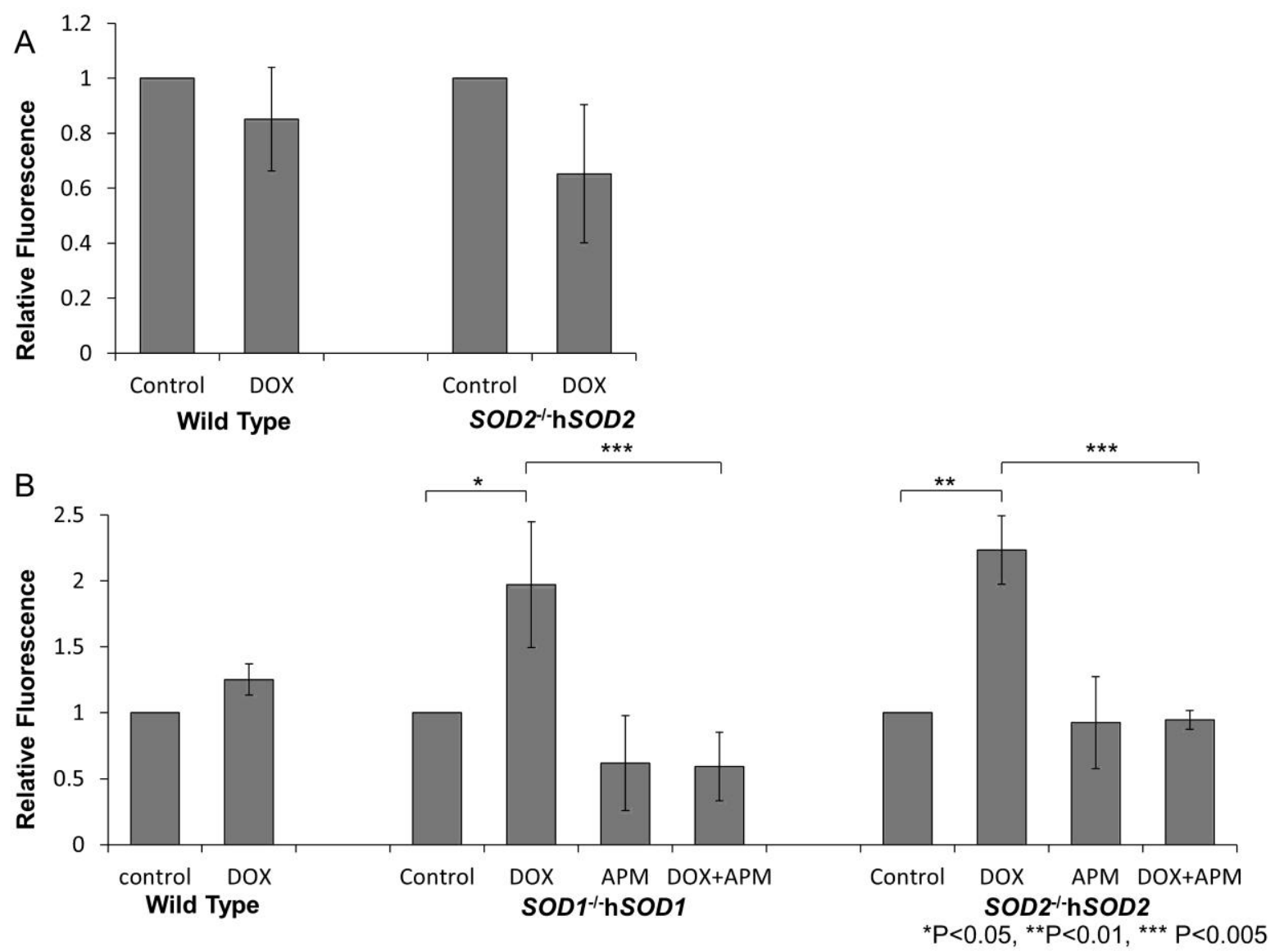
Figure 3

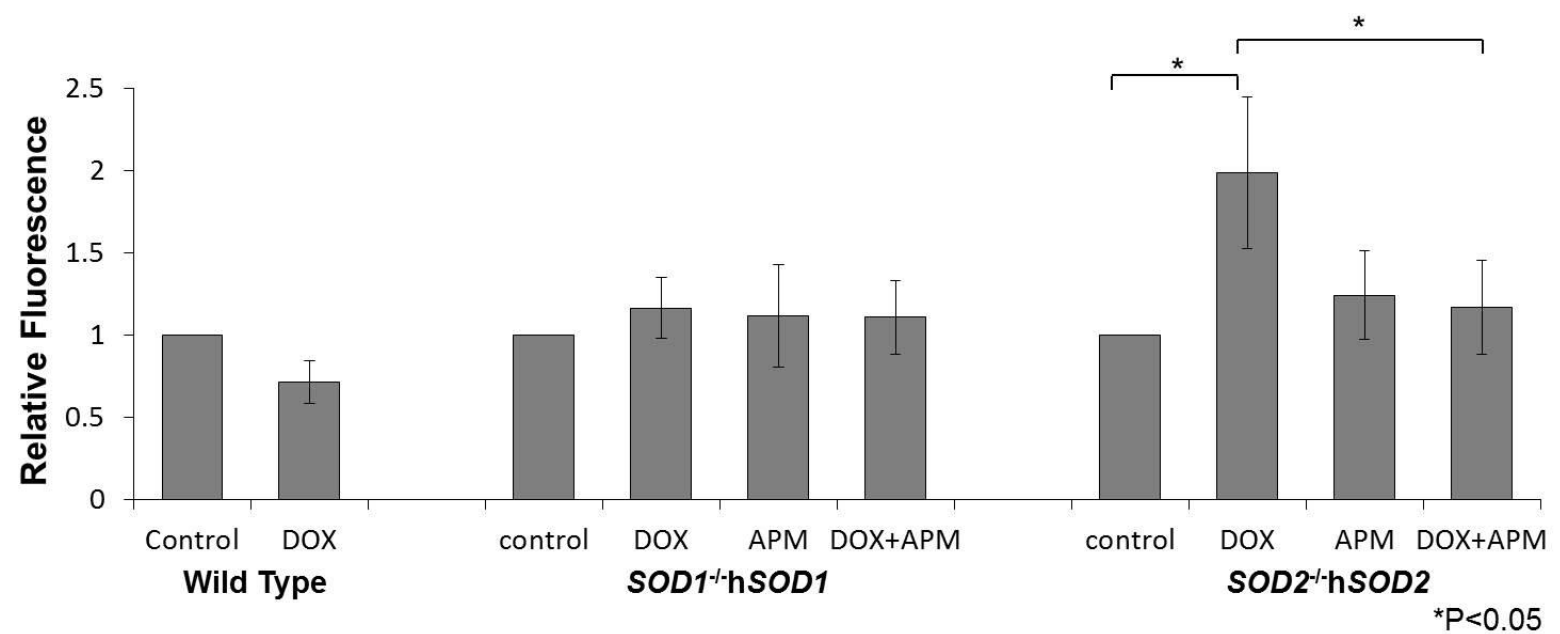


Figure 4

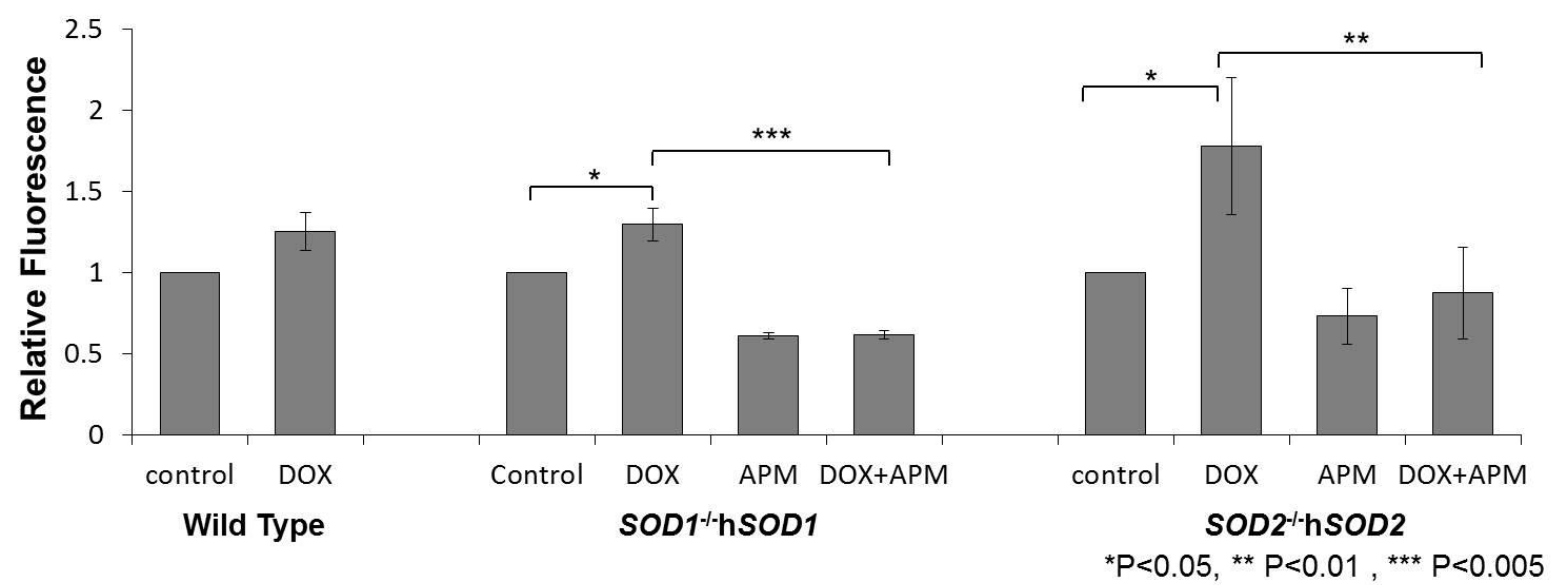

